\title{
Towards a Roadmap for Future Home Networking Systems: An Analytical Hierarchy Process Approach
}

Georgia Dede, Thomas Kamalakis, Member, IEEE, and Dimitris Varoutas, Member, IEEE

\begin{abstract}
Home Networking Systems (HNS) play a crucial role in achieving broadband service delivery to end users and are quickly becoming the next arena for telecom operators and companies. This emphasizes the need for a technology roadmap in order to address several key issues associated with the deployment of these systems. The present paper presents the results of the European project ICT-OMEGA road mapping effort for future HNS focusing on the most indicative and critical function, namely that of network extension. Taking into account the various social, economic and technological factors, three alternative technologies, namely the 802.11n, $60 \mathrm{GHz}$ and Power Line Communications (PLC) have been ranked, using the Analytic Hierarchy Process (AHP). Based on a number of expert surveys, the technology value of each solution is calculated. The results indicate that PLC possesses the largest potential for delivering broadband services in the home environment but also underlines the need for hybrid solutions. The results also reveal various crucial aspects of HNS deployment which are related to current research and standardization activities. A sensitivity analysis is also performed to ascertain the reliability of the results.
\end{abstract}

Index Terms-Analytic hierarchy process, decision making, home networking systems, IEEE802.11n, PLC, radio $60 \mathrm{GHz}$, technology roadmap.

\section{INTRODUCTION}

$\mathbf{H}$ OME Networking Systems (HNS) will play a crucial role in achieving end-to-end broadband service provision, enabling the penetration of the future internet. Traditionally, in-building networks, for instance in corporate or academic settings, have a tenfold higher capacity than their access points to the rest of the telecommunication infrastructure. Since Fiber-To-The-Home (FTTH) promises symmetric access data rates of at least $100 \mathrm{Mbit} / \mathrm{s}$ per household [1], HNS should support gigabit per second data transmission, limiting the latency time below $10 \mathrm{~ms}$. Inside new buildings, optical fiber-based systems (either glass or plastic) may provide the ultimate solution in terms of bandwidth and range. However, installing fiber cables inside older office buildings or dwellings is usually

Manuscript received October 08, 2010; revised February 10, 2011; accepted February 20, 2011. Date of publication June 16, 2011; date of current version August 24, 2011. This work was supported by the European Community's Seventh Framework Programme FP7/2007-2014 under Grant 213311 also referred to as OMEGA.

G. Dede is with the Department of Informatics and Telecommunications, University of Athens, Athens, Greece GR157841, and also with the Department of Informatics and Telematics, Harokopion University of Athens, Athens, Greece GR17471 (e-mail: gdede@di.uoa.gr)

T. Kamalakis is with the Department of Informatics and Telematics, Harokopion University of Athens, Athens, Greece GR17471 (e-mail: thkam@hua.gr).

D. Varoutas is with the Department of Informatics and Telecommunications, University of Athens, Athens, Greece GR157841 (e-mail: D.Varoutas@di.uoa. gr).

Digital Object Identifier 10.1109/JSYST.2011.2158683

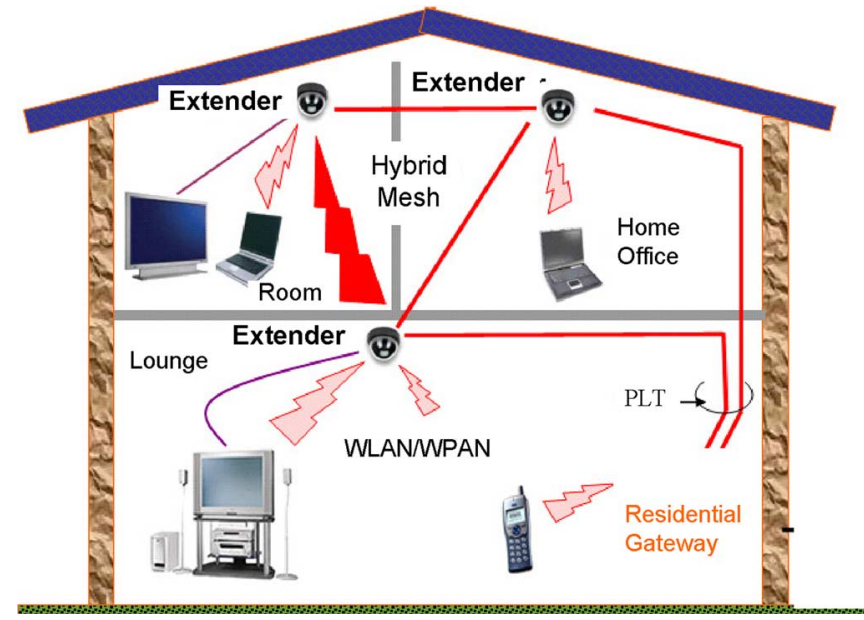

Fig. 1. Illustration of hybridization of technologies inside the HN.

not preferred, since it is accompanied with increased cost and user discomfort.

The ICT-OMEGA project aims to develop user-friendly HNS, capable of delivering high-bandwidth services and content, at a transmission speed of at least one gigabit per second [2]. The project aims to incorporate three different "no new wires" technologies, namely the optical wireless [3], radio [4]-[6] and Power Line Communications (PLC) [7] into a single inter Medium Access Control (inter-MAC) layer. The OMEGA inter-MAC is a technology independent layer, located between layers 2 and 3, providing common functionalities over heterogeneous communication systems. The inter-MAC is in charge to setup a resilient, reliable and easy to use gigabit home network that guarantees the quality and the continuity of services within the home environment [2]. The network consists of various interconnection points called extenders that spread inside the home, supporting the hybridization of the three aforementioned technologies. As shown in Fig. 1, network extension is a fundamental aspect of the OMEGA HNS [8]. It aims to extend the HNS coverage and allow the communication between devices having different Physical Layer (PHY) interfaces. Network extension can be realized at a wireless hotspot on the ceiling of the room or even at the terminal devices themselves. Conceivably, every network device may extend the network acting as a "multi-hopper," in the sense that it is able to process (receive and forward) traffic for which it is not an end point. The extender device may act as a router by forwarding data for other network nodes and can also generate and receive packets of its own supporting ad-hoc network functionalities. Each of the "no new wire" technologies considered in ICT-OMEGA may be used to provide the extension functionality. Taking into account that each comes 
with its own merits and shortcomings, it seems that no single technology will be able to satisfy every user requirement.

This paper seeks to shed light in this problem, contributing to the technological roadmapping of HNS in general. It considers three possible alternative technologies for network extension namely IEEE $802.11 \mathrm{n}, 60 \mathrm{GHz}$ radio and PLC. To rank these alternatives, the Analytic Hierarchy Process (AHP) methodology is used [9] as a fundamental part of an effective technology roadmapping introduced in [10]. The main objective of the paper is to evaluate the prospects of the various home networking technologies both from a technical and a socio-economic point-of-view. The paper builds on previous work [12], were the criteria and factors affecting the HNS deployment were identified and their importance was discussed. Based on these criteria and factors, the AHP framework is applied to its full extend to rank the several technological alternatives. AHP is a tool for complex decision making which reduces the overall process in a set of discrete subproblems, each of which can be tackled more easily. It has been used around the world on numerous occasions, in sectors such as government [13], business [14], industry [15], healthcare [16], technology [10], [11] education [17], and telecommunications [18]. As a representative example, in [18] the authors propose a model, based in AHP, which can be applied to improve the group decision making in selecting a telecommunication system that satisfies customer specifications. Interestingly enough, in [19] the concept of a System of Systems (SoS) collaborative formation mechanism is discussed using the AHP process.

The application of AHP in the present work reveals the prospects of the three technologies in question in future HNS deployment. To best of author's knowledge, this is a subject not previously addressed in the literature. According to the findings of the present work, PLC seems to take some precedence over the other two technologies but emphasis must also be placed in hybrid solutions incorporating multiple technologies. Several issues concerning the device performance and component cost are revealed and the relevance of current research and standardization activities is discussed. In order to validate the reliability of the results, the authors extend the AHP technology value framework introduced in [10] incorporating sensitivity analysis and Monte Carlo simulation. This serves as a means to investigate how uncertainty influences the final ranking. The rest of the paper is organized in the following sections: In Section II, the motivation behind the roadmapping effort for the technologies of choice is analyzed. In Section III, the basic notions of the AHP method are presented. Moreover, the expert surveys conducted within the AHP framework are described in Section IV. Section V illustrates the results obtained by the AHP methodology concerning the extension functionality and HNS in general. The results of the sensitivity analysis are presented in Section VI. Some concluding remarks are given in Section VII.

\section{MOTIVATION FOR AN HNS ROADMAP}

As mentioned in Section I, there are various technology solutions that could be considered for network extension, each with their own particular characteristics. Radio systems, such as WiFi, are already commercially available and $802.11 \mathrm{n}$ promises up to $600 \mathrm{Mb} / \mathrm{s}$ data rates using multiple-input multiple output
(MIMO) techniques [4], but the actual network throughput should be lower. Systems operating at the unlicensed $60 \mathrm{GHz}$ band [5] and short range Ultra Wide Band (UWB) [6] systems can provide higher data rates. Wireless gigabit-per-second transmission is feasible at $60 \mathrm{GHz}$, but such systems have not reached full technological maturity. State-of-the-art PLC [7] provide hundreds of megabit-per-second wireline connectivity using the already installed power cables of the house. Extending them in the gigabit regime is however a challenge because of the particularities of the power line channel. Optical Wireless Systems (OWS) [1] may also provide high data rates, possibly reaching $10 \mathrm{~Gb} / \mathrm{s}$ in the future, in either the infrared or visible spectrum region. However, there are still important technical limitations in their application. In Line-of-Sight (LOS) OWS configurations, blocking is a serious issue. In diffuse configurations, where there is no need for LOS path, one obtains a poorer signal to noise ratio.

The above discussion illustrates that, as envisioned in OMEGA, future HNS will probably consist of hybrid systems and technology roadmapping is key in ensuring their smooth deployment. This paper aims to contribute towards this end, by ranking three possible alternative technologies for network extension, namely IEEE 802.11n, Radio $60 \mathrm{GHz}$ and PLC. Optical wireless systems are not considered in this work, since the majority of the experts believed that this technology is still relatively quite immature. For example, it remains unclear which optical wireless configuration will prevail from a number of possible choices [20], including Visible Light Communications (VLC) and infrared (IR) systems which can be LOS, diffuse or both. Such issues prevent reliable forecasting of several performance-related measures. Furthermore UWB was not considered in the HNS roadmap since they can provide high bandwidth short range links at small distances, but at distances longer than $10 \mathrm{~m}$ the throughput is comparable to that of $802.11 \mathrm{~g}$ [21].

In addition to technical complexities, the network designer must take into account many economic and social issues affecting the acceptance of HNS from the wider public. For example, the system cost becomes of paramount importance as we move closer to the user premises. It is easy to understand that the prospects of HNS are influenced by a blend of performance, cost, health and security related features. In view of such complexities, the need for an HNS roadmap, addressing all these issues, becomes evident in order to reach a consensus about the set of needs and the technologies that are required to satisfy those needs.

\section{Methodology Description}

\section{A. AHP Framework}

The AHP framework incorporating the technology value evaluation [12] is depicted in Fig. 2. On the first level, the objective of the decision making process is defined and the alternative courses of action (in our case the alternative technological solutions) are identified. The second level, shown in Fig. 2, comprises of the definition of the criteria $C_{k}$ where $k$ is an integer with $1 \leq k \leq N$, affecting the decision making process. A criterion is a particular aspect that needs to be taken 


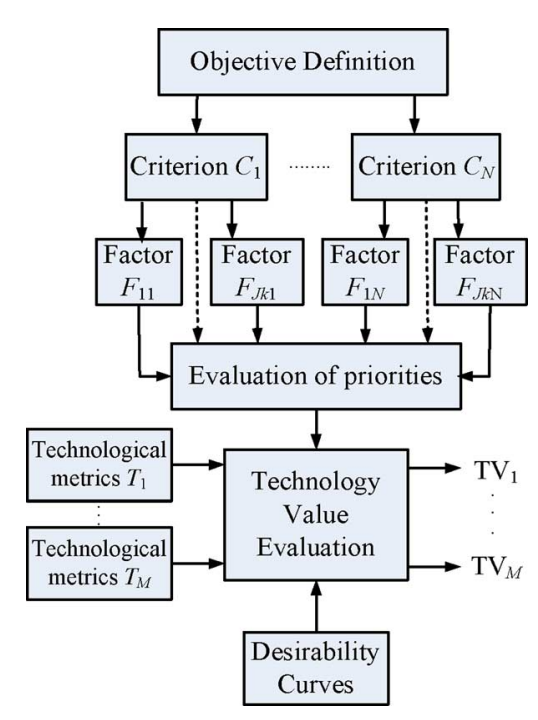

Fig. 2. The AHP hierarchical model incorporating the evaluation of the technology values for each technology.

into account when deciding in favour or against an alternative. In the third level, a number of factors $F_{j \kappa}$ are identified for each criterion $C_{k}$ where $j$ is an integer with $1 \leq j \leq J_{k}$. A factor is an indicative attribute that characterizes a criterion. The factors can be either quantified in terms of numerical values (for example in the case of the achieved bit rate, in $\mathrm{Mb} / \mathrm{s}$ ) or using a qualitative scale (for example a 6-point scale: Excellent- $\mathrm{E}$, very good $-\mathrm{VG}$, good $-\mathrm{G}$, average $-\mathrm{A}$, poor-P, unacceptable-U).

The priorities of the alternatives are evaluated by determining the weights of the criteria and their corresponding factors based on the opinion of experts. To estimate the weights of the criteria, pairwise comparisons [12], [21] are used, according to which, the experts are required to perform a series of comparisons of the various criteria involved in combinations of two. After the experts have completed these comparisons, one can calculate the average weights $w_{k}$ of the various criteria involved and obtain their ranking, using several mathematical methods such as the eigenvalue method [21]. The same procedure is carried out for the factors of each criterion and the weights of the factors $f_{j k}$ are estimated. This is an important step in the AHP decision making framework, since it allows for the ranking of the various alternatives.

\section{B. Technology Value Estimation}

Fig. 2 already suggests that the technology evaluation is based on the values of the technological metrics $t_{n j k}$ which represents the actual value of factor $F_{j k}$ for the $n$th technology. The present and future values of the technological metrics are determined by the experts through a series of surveys. For future values of $t_{n j k}$ experts need to make a forecast based on their experience. For each value of $t_{n j k}$ we can assign a desirability value by specifying a desirability function $V_{j k}$. This function maps the values of $t_{n j k}$ to real numbers between 0 and 100 and is also determined by collecting the opinion of the experts. More specifically, the interval of value range of the factors is divided into a number of subintervals and experts are requested to provide a desirability value from 0 (the worst desirability value) to 100 (the best desirability value) for the midpoints of each subinterval. The desirability function is calculated by averaging the values provided by the experts. The function values at all other points may be determined using linear interpolation. Once $V_{j k}$ and $t_{n j k}$ are calculated then $V_{j \kappa}\left(t_{n j \kappa}\right)$ determines the desirability level of the factor $F_{j k}$ for the $n$th technology. However, in determining the overall desirability of the technologies one must also take into account the relative importance of each factor in the decision making process. The weights $f_{j k}$ determine the importance of factor $F_{j k}$ related to the rest of the factors of criterion $C_{k}$. Since the weight of $C_{k}$ is $w_{k}$, one deduces that the weight of factor $F_{j k}$ with respect to all other factors is $w_{k} f_{j k}$. Therefore in estimating the overall desirability of each technology (i.e., its technology value) one should calculate the weighted sum of $V_{j \kappa}\left(t_{n j \kappa}\right)$ with respect to $w_{k} f_{j k}$ :

$$
\mathrm{TV}_{n}=\sum_{k=1}^{N} \sum_{j=1}^{J_{k}} w_{k} f_{j k} V_{j k}\left(t_{n j k}\right)
$$

In (1), $\mathrm{TV}_{n}$ is the Technology Value (TV) of the $n$th technology and ranges between 0 and 100, quantifying the appropriateness of a technological solution over time. It is interesting to note that, according to the technology value for the $n$th technological alternative can be thought of as the sum of the technological values of the factors $\mathrm{TV}_{n j k}=w_{k} f_{j k} V_{j k}\left(t_{n j k}\right)$ for the alternative in question. One can also define the technological value of criterion $C_{k}$ for the $n$th technological alternative by summing up the technological values of its factors,

$$
\mathrm{TV}_{n k}=\sum_{j=1}^{J_{k}} \mathrm{TV}_{n j k}
$$

\section{SuRVEys Design AND Participants}

\section{A. Definition and Weights of Criteria and Factors}

Table I summarizes the factors and criteria pertinent for the extension functionality, including their description. A detailed discussion on how the criteria and factors were identified and the calculation of their weights can be found in [12]. Hereafter, the basic conclusions are summarized and can be drawn from Table I. Twenty five experts in HNS have participated in the pairwise comparisons that was conducted during a period of three months in September-November 2009. According to the opinion of the experts, all criteria, except from design issues, have more or less the same weight (ranging between 19\% to $24 \%$ ), suggesting that all corresponding issues have equal bearing. Design issues are deemed of secondary importance probably because there are still many important technological matters to be resolved in order to provide reliable and cost-effective network extension functionality. The situation is quite different when one considers the factor weights. Regarding the system trustworthiness/confidence criterion, it is clear that health issues are the most important aspect to consider reflecting the growing public concern on this subject [24], [25]. Several standards [26] are addressing the health concerns such as the IEEE C95.1-2005 [25]. 
TABLE I

CRITERIA AND FACTORS FOR THE EXTENSION FUNCTIONALITY

\begin{tabular}{|c|c|c|c|}
\hline \multirow{3}{*}{$\begin{array}{l}\text { Criteria- } \\
\text { Factors } \\
F_{11}\end{array}$} & \multicolumn{2}{|r|}{ Description } & \multirow{3}{*}{$\begin{array}{l}\text { Weight } \\
41.37 \%\end{array}$} \\
\hline & \multicolumn{2}{|c|}{$C_{1}:$ System Performance $\left(w_{1}=20.38 \%\right)$} & \\
\hline & Range & $\begin{array}{l}\text { For wireless this is the distance that can } \\
\text { be covered in a line-of-sight } \\
\text { configuration. For PLC this is } \\
\text { maximum cable length. }\end{array}$ & \\
\hline$F_{12}$ & $\begin{array}{l}\text { Upstream Bit } \\
\text { Rate }\end{array}$ & $\begin{array}{l}\text { The maximum upstream PHY-layer bit } \\
\text { rate that a single user terminal can } \\
\text { achieve when connected to the extender }\end{array}$ & $23.54 \%$ \\
\hline$F_{13}$ & $\begin{array}{l}\text { Downstream } \\
\text { Bit Rate }\end{array}$ & $\begin{array}{l}\text { The maximum downstream PHY-layer } \\
\text { bit rate that a single user terminal can } \\
\text { achieve when connected to the extender }\end{array}$ & $35.09 \%$ \\
\hline \multicolumn{4}{|c|}{$C_{2}:$ Simplicity of Use $\left(w_{2}=19.18 \%\right)$} \\
\hline$F_{21}$ & Plug and Play ${ }^{*}$ & $\begin{array}{l}\text { Once installed, is the system plug and } \\
\text { play? }\end{array}$ & $54.52 \%$ \\
\hline$F_{22}$ & $\begin{array}{l}\text { Compatibility } \\
\text { with legacy } \\
\text { devices }^{*}\end{array}$ & $\begin{array}{l}\text { Is the system compatible with existing } \\
\text { networks and home appliances? }\end{array}$ & $45.48 \%$ \\
\hline \multicolumn{4}{|c|}{$C_{3}:$ Design $\left(w_{3}=13.36 \%\right)$} \\
\hline$F_{31}$ & $\begin{array}{l}\text { Design- } \\
\text { Integration to } \\
\text { home } \\
\text { environment" }\end{array}$ & $\begin{array}{l}\text { How well do the OMEGA systems } \\
\text { incorporating system functionality fit } \\
\text { with the overall household decoration? }\end{array}$ & $37.41 \%$ \\
\hline$F_{32}$ & $\begin{array}{l}\text { Volume of } \\
\text { Extender }\end{array}$ & $\begin{array}{l}\text { The volume of the extender device in } \\
\mathrm{cm}^{3} \text {. }\end{array}$ & $33.66 \%$ \\
\hline$F_{33}$ & $\begin{array}{l}\text { Weight of } \\
\text { Extender }\end{array}$ & $\begin{array}{l}\text { The weight of the extender device in } \\
\mathrm{kg} \text {. }\end{array}$ & $28.94 \%$ \\
\hline$F_{41}$ & $\begin{array}{l}\text { Cost of } \\
\text { Extender }\end{array}$ & $\begin{array}{l}\text { Economic }\left(w_{4}=22.67 \%\right) \\
\text { The cost of purchase of the extender } \\
\text { device. }\end{array}$ & $39.48 \%$ \\
\hline$F_{42}$ & $\begin{array}{l}\text { Annual Cost of } \\
\text { the most } \\
\text { expensive } \\
\text { component in } \\
\text { the technology }\end{array}$ & $\begin{array}{l}\text { The annual cost in order to repair the } \\
\text { most expensive component in the } \\
\text { technology in case of damage or failure. }\end{array}$ & $22.44 \%$ \\
\hline$F_{43}$ & $\begin{array}{l}\text { Annual } \\
\text { operation cost }\end{array}$ & $\begin{array}{l}\text { It mostly includes the influence of } \\
\text { power consumption on operation cost }\end{array}$ & $38.08 \%$ \\
\hline$F_{51}$ & $\begin{array}{l}C_{5}: \text { System Tr } \\
\text { Security/Privac } \\
y^{*}\end{array}$ & $\begin{array}{l}\text { stworthiness/Confidence }\left(w_{s}=24.38 \%\right) \\
\text { Are security and privacy issues } \\
\text { important? }\end{array}$ & $17.64 \%$ \\
\hline$F_{52}$ & Health issues ${ }^{*}$ & $\begin{array}{l}\text { Are health issues important? (meeting } \\
\text { radiation exposure, eye-safety, skin- } \\
\text { safety, etc standard) }\end{array}$ & $48.19 \%$ \\
\hline$F_{53}$ & $\begin{array}{l}\text { Mean Time } \\
\text { between failure } \\
\text { of extender }\end{array}$ & $\begin{array}{l}\text { Mean Time that intervenes between } \\
\text { two consequent failures of the extender } \\
\text { device }\end{array}$ & $34.17 \%$ \\
\hline
\end{tabular}

* These factors are quantified using a qualitative scale (ex. Excellent, Good, Average, Poor)

According to Table I, security seems to be a minor concern. This is possibly a reflection of the fact that the HNS vendor can implement security-related methods on a protocol basis. In light of this, the Wi-fi Protected Access WPA2 [27] security protocol is incorporated in the IEE802.11n. Regarding power line communications there are two intrinsic levels of security in PLC equipment: a DES (Date Encryption Standard) encryption and the possibility of setting up separate networks on the same electric circuit with two different encryption keys that can be configured using software usually provided with the equipment [28]. Interestingly enough $60 \mathrm{GHz}$ signals remain confined within a room offering both security and interference advantages. Concerning the design criterion, experts seem to believe that the design/integration to the home environment tends to be the most important aspect. It is also deduced that both the volume and weight are important issues for both practical and
TABLE II

SURVEY DESCRIPTION

\begin{tabular}{llll}
\hline \hline$\#$ & \multicolumn{1}{c}{ Description } & Duration (mm/yy) & No of Experts \\
\hline 1 & $\begin{array}{l}\text { Technology metrics for IEEE } \\
802.11 \mathrm{n}\end{array}$ & $02 / 10-03 / 10$ & 11 \\
2 & Technology metrics for 60GHz & $02 / 10-03 / 10$ & 12 \\
3 & Technology metrics for PLC & $02 / 10-03 / 10$ & 10 \\
4 & Desirability functions & $02 / 10-03 / 10$ & 31 \\
\hline \hline
\end{tabular}

marketing reasons. Regarding the economic criterion, great importance is placed on both the component price and the influence of power consumption on operation cost emphasizing the need for energy efficient (green) devices. Regarding the simplicity of use criterion, the plug and play feature is considered somewhat more important than the compatibility with legacy systems - probably because this feature is already present in Digital Subscriber Line (DSL) modems as well as IEEE802.11 wireless routers. Compatibility with legacy devices is also an important issue to take into account. Future adopters would prefer the systems incorporating extension functionalities to be easily mounted on their laptops and other appliances much like WiFi cards on USB sticks. As far as performance is concerned, the experts seem more concerned about the range rather than the maximum achievable bit rate of the system. It should be noted that as far as $802.11 \mathrm{n}$ is concerned, range refers to a LOS configuration, since non-LOS is rather difficult to evaluate since one must take into account the actual room/house characteristics. Downstream bit rate is also important in view of many popular services where bandwidth requirements are asymmetric. The importance of upstream data rate is not trivial however (about 24\%) probably because of several emerging symmetric service technologies, such as on-line gaming, distributed and peer-to-peer applications [29], etc.

\section{B. Surveys for Technology Value Evaluation}

Four additional surveys were carried out in order to evaluate the technological metrics and the desirability functions, required for the estimation of the technology values for the various alternative technologies. The surveys are briefly described in Table II.

The survey design was extensively discussed among the several OMEGA partners. The feedback from the telecom operators was interesting enough and very useful for the final survey design taking into account the user perspective in both the performance-related issues and the socio economic aspects. The experts are highly trained employees with many years experience from the various organizations inside the OMEGA project consortium [30], which constitutes a well balanced blend between industry and academia from many parts of Europe (France, Italy, Germany, Spain, Austria, Slovenia, UK and Greece). Their expertise lies primarily in the field of HNS technologies. The aforementioned surveys were conducted by a web-based survey/roadmapping platform incorporating the AHP framework, where experts log on to the platform and fill out the questionnaires. The web-platform has been developed and maintained by the University of Athens. 

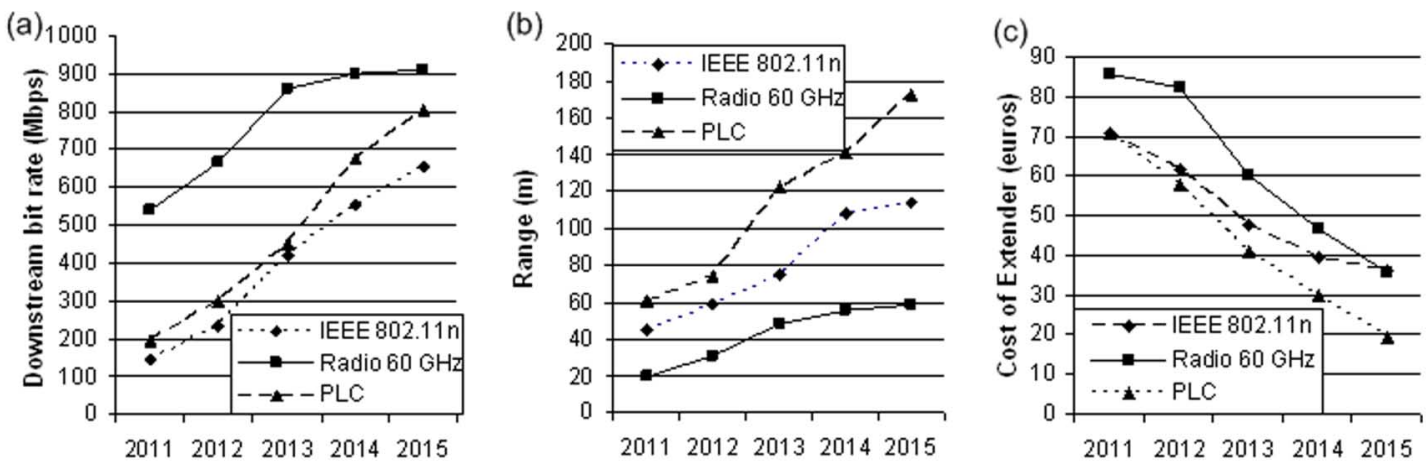

Fig. 3. Forecasts for various technological metrics.

\section{RESULTS AND DISCUSSION}

In this section, the results of the surveys in Table II are discussed and the Technology Value of each alternative for the interval 2011-2015 are calculated and discussed.

\section{A. Technological Metric Forecasting}

Fig. 3 illustrates some examples of the technological metrics calculated from the averaging of data provided by the first three surveys of Table II. Regarding the downstream data rate in Fig. 3(a), the experts think that $60 \mathrm{GHz}$ systems will most likely take precedence over the other technologies. This is because of the license-free spectrum between 57 and $64 \mathrm{GHz}$ which is available for data transmission in this band [31]. It should be noted that $60 \mathrm{GHz}$ systems can be realized using Complementary Metal-Oxide-Semiconductor (CMOS) circuits [31]. Such advances, together with some other promising features of the $60 \mathrm{GHz}$ band have led the standardization activities. IEEE has formed 802.15.3.c study group to develop a millimeter-wave-based alternative PHY for wireless personal area network (WPAN) [32]. Despite the bandwidth abundance in the $60 \mathrm{GHz}$ band, on the average the experts predict that commercial systems will provide slightly less than $1 \mathrm{~Gb} / \mathrm{s}$ by 2015, probably because of technology-related performance issues.

PLC systems come second, with predicted data rates of the order of several hundred megabit per second. Restrictions in these systems originate mainly because of the characteristics of power line channels. Advanced modulation schemes such as Orthogonal Frequency Division Multiplexing (OFDM) can be used to push the system capacity to its limits [33], [34], [35]. Many organizations have developed specifications for PLC, including the HomePlug Powerline Alliance, and Universal Powerline Association. The ITU-T adopted Recommendation G.hn/G.9960 as a standard for high-speed powerline, coax and phoneline communications. IEEE P1901 is an IEEE working group developing the global standard for high speed powerline communications.

IEEE $802.11 \mathrm{n}$ comes third in terms of downstream capacity, achieving its maximum data rate $(600 \mathrm{Mb} / \mathrm{s})$ near the end of the study period. $802.11 \mathrm{n}$ incorporates both MIMO and OFDM as a means to increase the available data rate. It is interesting to note that actual throughput performance for wireless radio system may be less because of MAC-related issues. Within 802.11n several MAC enhancements are being considered in order to alleviate this problem [36]. Similar conclusions can be drawn from the upstream bit rate forecasts.

The results regarding the range of the three technologies are shown in Fig. 3(b). As expected $60 \mathrm{GHz}$ systems have significant lower range because of the properties of electromagnetic radiation in this part of the spectrum, than the PLC and the $802.11 \mathrm{n}$ solutions. Hence, range seems to be a limitation for the $60 \mathrm{GHz}$ technology. At lower frequencies, say in UWB systems, coverage may vary significantly with frequency and there are five band groups covering a frequency range from $3.1 \mathrm{GHz}$ to $10.6 \mathrm{GHz}$ corresponding to a coverage range between $10 \mathrm{~m}$ and $1.56 \mathrm{~m}$, respectively [37]. Because of relatively smaller changes in frequency, coverage range does not change dynamically for the $60-\mathrm{GHz}$ radio. The $60 \mathrm{GHz}$ channel generally exhibits optical-like properties since the strongest components tend to be LOS. At this band there is a large free space propagation loss (about $20 \mathrm{~dB}$ more than that in $5 \mathrm{GHz}$ band) which could be overcome by the use of high gain directional antennas in order to improve the signal coverage [38], which are feasible to implement due to the relatively short wavelengths $(\cong 5 \mathrm{~mm})$. The short wavelengths in this band impose some serious challenges such as greater signal diffusion and difficulty diffracting around obstacles. The transmission of $60 \mathrm{GHz}$ signals is strongly influenced by surrounding obstacles and walls, as well as shadowing [39]. People moving inside the line of sight may attenuate the signal by as much as $15 \mathrm{~dB}$ and objects such as furniture, walls, doors and floors found in indoor environments can also be problematic. Because of their optical-like nature, $60 \mathrm{GHz}$ signals cannot penetrate room walls rendering each room into a separate cell where the whole system capacity is possible [40]. This of course necessitates the use of one hotspot per room. These facts are reflected in Fig. 3(b), where the experts seem to believe that the range of the $60 \mathrm{GHz}$ would reach some tens of meters through the study period.

Link characteristics are very different in the case of IEEE $802.11 \mathrm{n}$, where the penetration loss is much less and rich multipath propagation exists to provide diversity. As a result, the range can reach up to hundreds of meters, which coincides with the experts point of view depicted in Fig. 3(b). 802.11n extends the original concepts of 802.11 and includes many new options to improve the quality of the wireless link and thereby to increase both data rate and range. The coding scheme for $802.11 \mathrm{n}$ is better than earlier versions of the standard and this results in 
(a) Downstream Bit Rate

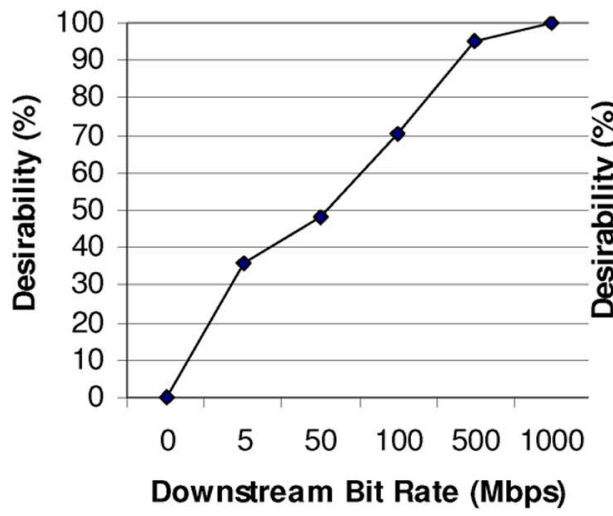

(b) Cost of the Extender

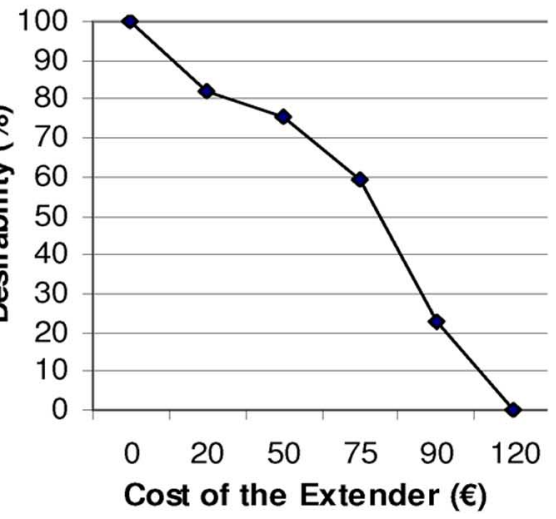

Fig. 4. Examples of desirability function curves.

more data bits being transmitted in the same size channel [36]. In addition, $802.11 \mathrm{n}$ allows channel bonding that will essentially double the data rate. Contrary to other wireless local area networking standards, $802.11 \mathrm{n}$ maintains high-speed connections at greater than $90 \mathrm{~m}$. In 802.11 networks, a single wireless router can be used to achieve connectivity over multiple rooms. Nevertheless, the coverage range in the IEEE $802.11 \mathrm{n}$ will vary depending on the environment as well as on the capability of the user and access point.

As shown in Fig. 3(b), PLC technology takes precedence compared to the other technology alternatives. According to Table I, in the case of PLC, the range is related to the meters of the wires used for the signal transmission within the house. It is deduced that the maximum cable length will reach around 170 meters in 2015. In fact, the range of the PLC wires is independent from the limits mentioned for IEEE $802.11 \mathrm{n}$ and $60 \mathrm{GHz}$. The only limiting factors concerning the power lines communication originate from noise, attenuation and multipath propagation [33].

The last example of technological metric forecasting is the cost, shown in Fig. 3(c). The experts predict that the cost will be higher for the $60 \mathrm{GHz}$ solution, especially in earlier years. Today's $60-\mathrm{GHz}$ technology depends on relatively expensive and GaAs semiconductors, but as discussed previously, various works indicate that silicon chips can do the job with much less power and at a fraction of the cost. Cost reduction in all three technologies depends on production volume and therefore the demand for future home networking equipment. If users are attracted by broadband services such as HDTV, online gaming, high-definition content sharing and distribution between enduser devices such as the storage device and user terminals, then the increase in production volumes will promote further cost reduction [41]. Toward this end, standardization is also another important element that may reduce the cost of the network components.

\section{B. Desirability Function Curves}

Fig. 4 illustrates some examples of desirability function curves $V_{k j}$ for the cases of a) downstream bit rate and b) cost for the extender systems. Experts are strict when concerned with downstream rather than upstream traffic. For example

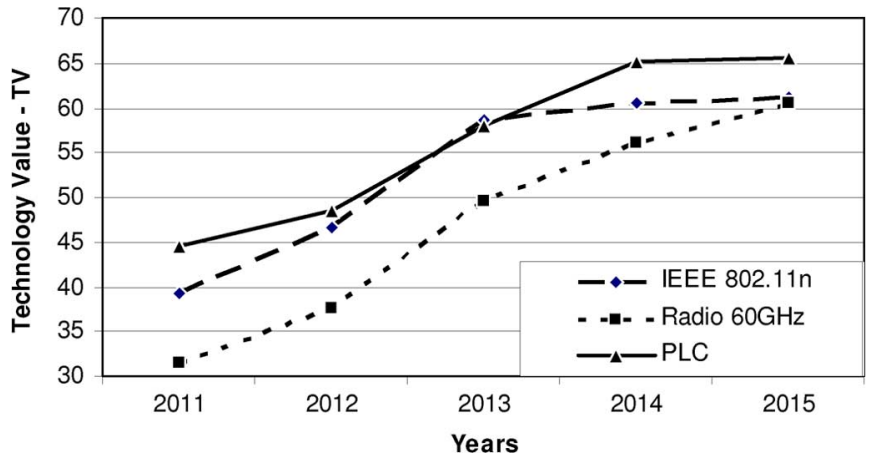

Fig. 5. TV for the technology alternatives for network extension.

a $100 \mathrm{Mb} / \mathrm{s}$ downstream data rates maps to $70 \%$ satisfaction level, while for upstream data rate this is much higher. This reflects the asymmetric nature of many broadband services and particularly HDTV where high downstream data rates are important for high quality service provision.

The desirability curve for the cost is also interesting emphasizing the need for low cost solutions. Much like access networks, the commercial prospects of home networks are much more sensitive to component cost than say, core networks, since the equipment is now installed at the user premises and not some remote central office owned by the telecom operator. According to the experts, the systems must be priced below $100 €$ in order to be attractive from a user point-of-view.

\section{Estimation of the Technology Value}

The technology value of each alternative solution was evaluated through (1) in each time period, once the desirability functions $V_{j k}$ and the technological values $t_{n j k}$ are determined by the appropriate expert surveys described in Table II. As mentioned in Section III, the technology value for the $n$th technological alternative can be thought of as the sum of the technological values of the factors $\mathrm{TV}_{n j \kappa}$. Fig. 5 shows the technology values calculated for each of the alternative networking technologies considered. The results are also indicative for other network devices as well (terminals, etc). The results of Fig. 5 will be further elaborated in Section V-D considering the technological values of the factors and criteria, which determine the final ranking of the alternatives. 

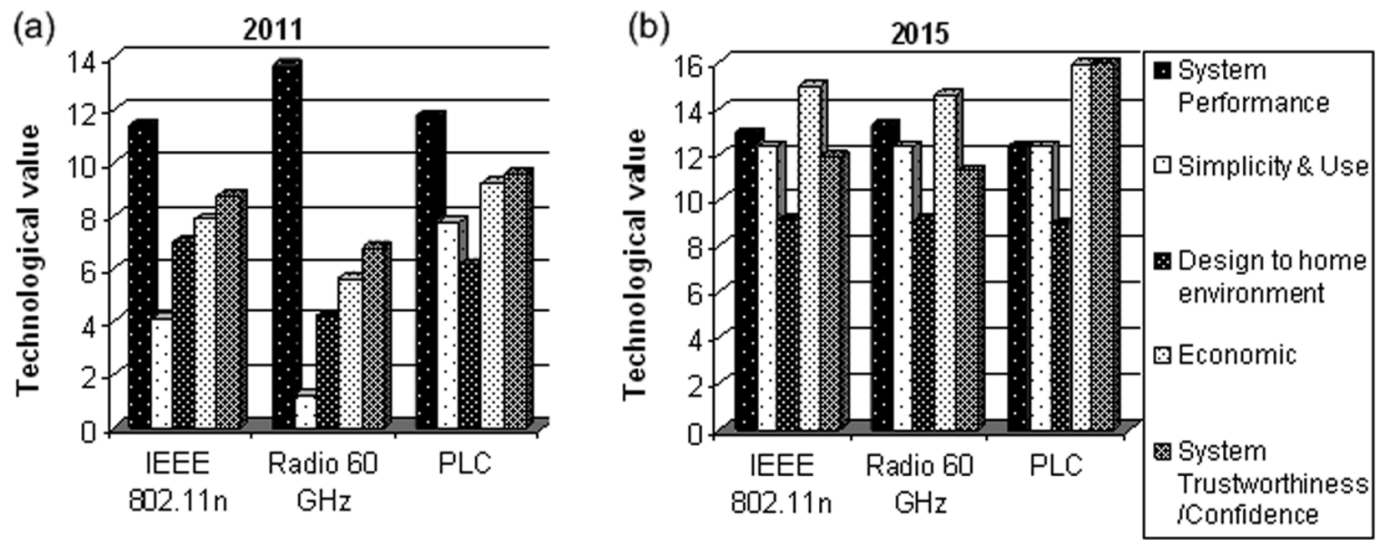

Fig. 6. Technological values of Criteria (a) 2011 (b) 2015.

Fig. 5 suggests that the technology value of each technology is improved over time as a consequence of the increased performance and cost reduction. The graph indicates that PLC seems to have the highest short-term potential. For both PLC and 802.11n systems, the TV eventually level off after 2014, suggesting that these technologies will reach maturity within the next two to three years. The situation is different for the $60 \mathrm{GHz}$ systems for which the TV is increasing even beyond 2014. Interestingly enough, $60 \mathrm{GHz}$ systems seem to achieve the same TV as $802.11 \mathrm{n}$ in 2015 suggesting that in the long run, they may serve as the technology of choice for wireless home access. It is also interesting to consider the fact that PLC and 802.11 n have pretty much the same TV in 2013.

Hybrid radio/PLC systems, combining the merits of both technologies could also provide an alternative. Products combining both technologies at the PHY have already been commercialized. Within ICT/OMEGA, all three technologies are combined in a single inter-MAC layer. The issue of hybridization is more interesting when the PLC and the $60 \mathrm{GHz}$ systems are combined together: $60 \mathrm{GHz}$ can provide high bandwidth wireless connection within the room while PLC can be used to extend the connectivity across multiple rooms of the house. In order for PLC to provide the future home network backbone however, its capacity must be extended in the Gigabit per second regime. On a more general sense, the capacity of the home network backbone is an important issue for future $\mathrm{HN}$ deployment. In the long run, fiber either multimode or plastic would provide the best solution, potentially offering one order of magnitude higher capacity than PLC at the expense of installing additional wires inside the house. Towards this concept, radio-over-fiber (RoF) techniques may provide an interesting potential [35]. The RoF concept relies on modulating an optical source at by the radio signal (instead of its baseband form) and distributing it through optical fiber to the various hotspots. In this manner, the hotspot/base station equipment is much simpler, since no frequency up/down conversion is required at the various base stations. At $60 \mathrm{GHz}$ however, it is impossible to modulate the LASER using direct modulation and an external modulator should be used, increasing the cost. In any case, a RoF-based backbone network solution using high frequency radio signals presents with several technical challenges and will not be easily made commercially available in the near future.
Fig. 5 suggests that shorter term network extension would be provided by PLC. Optical wireless technologies combined with either fiber or PLC could also provide a longer term alternative for distributing data at gigabit bit rates inside the house. The combination of visible light communication (VLC) and PLC has already been proposed [42]. In this approach, white LED of ceiling lamps used for illumination, are also modulated in order to provide wireless data range. The various white LED lamps can be connected using a PLC network, providing both power supply and backbone connection. Such systems can be used for data broadcast, but do not provide upstream connectivity (i.e., from the terminal to the hotspot).

\section{Technological Value of Each Factor and Criterion}

Fig. 5 illustrates the total Technology Value of each alternative, but it is also interesting to consider its various components, i.e., the TV of each criterion and each factor as defined in Section II-B. It seems to be that PLC receives the highest technology values in the most cases. Fig. 6(a) and (b) depict the technological values of criteria in 2011 and 2015, respectively. Fig. 6 suggests that PLC rates better both in the beginning and the end of the study period in terms of system trustworthiness and the economic criterion defined in Table I. Simplicity and integration to home environment are generally favourable for PLC in 2011, but eventually level off for all three technologies in 2015. The 802.11 also rates high in terms of home environment integration in 2011 while the $60 \mathrm{GHz}$ systems rate high in terms of performance but do not meet well with other criteria, especially in 2011, which justifies the precedence of the other alternatives TVs over the $60 \mathrm{GHz}$ solution.

Fig. 7 indicates the technological values of the factors for each technology averaged throughout the study period. The figure also contains useful information, breaking down the contribution of each factor in the total technology value of a solution. Interestingly enough, all three technologies accumulate more technological value because of downstream bit rate performance than in terms of upstream data rate and range. Downstream data rate is in fact the most important asset for $60 \mathrm{GHz}$ systems. Plug-and-play carries high importance for 802.11 and PLC, probably because these technologies are already commercially available. The device cost is also an important asset for 802.11 and PLC. Health issues constitute 


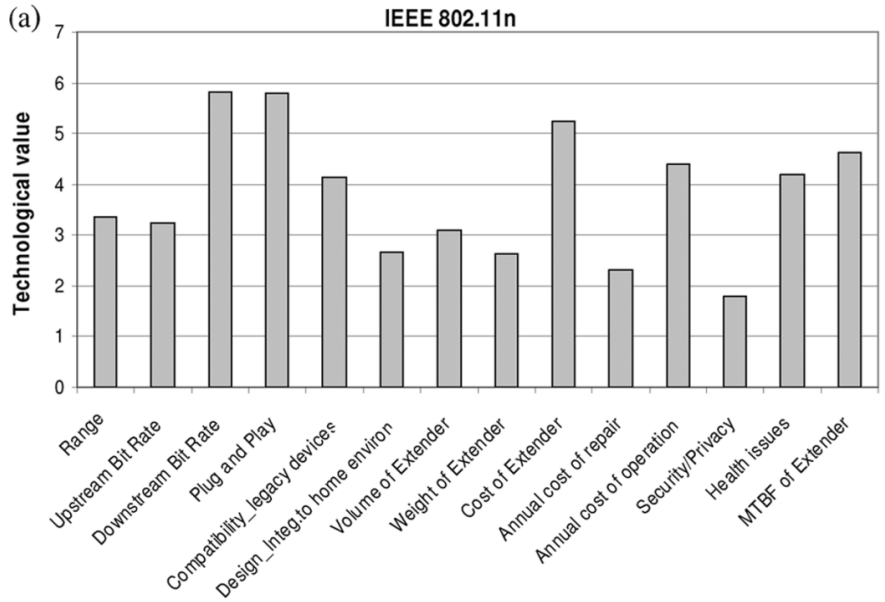

(b)
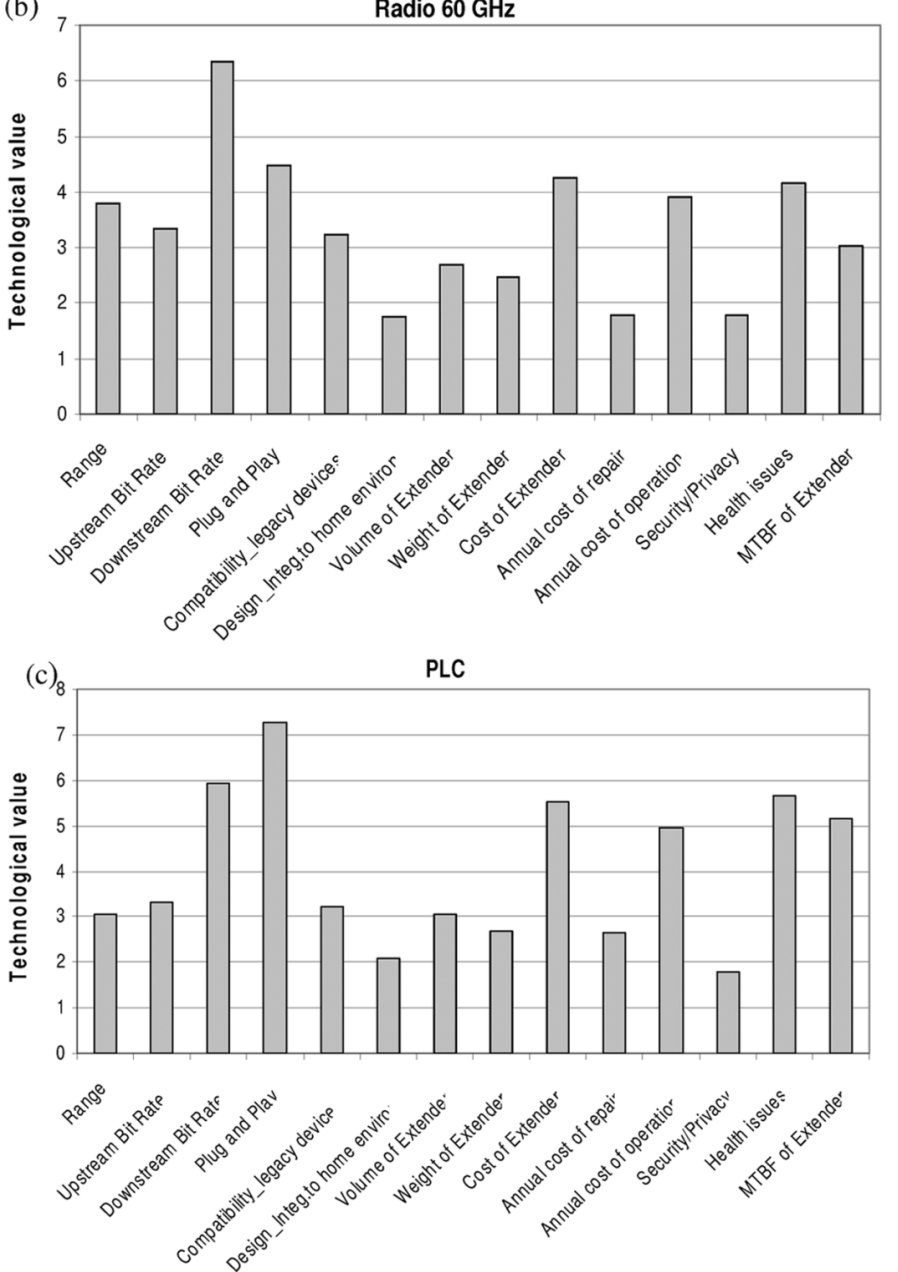

Fig. 7. Mean technological values: (a) IEEE 802.11 n, (b) Radio $60 \mathrm{GHz}$, and (c) PLC.

an important component in the technological value of PLC, especially in light of the public concern on the impact of radio radiation in wireless technologies.

Comparing the technological values of the various factors, one deduces that up to a point, the technologies are complimentary. Taking into account the previous discussion in this section, as well as the fact that the technology values in Fig. 5 of PLC and $802.11 \mathrm{n}$ are rather close, especially near 2013 , it seems that
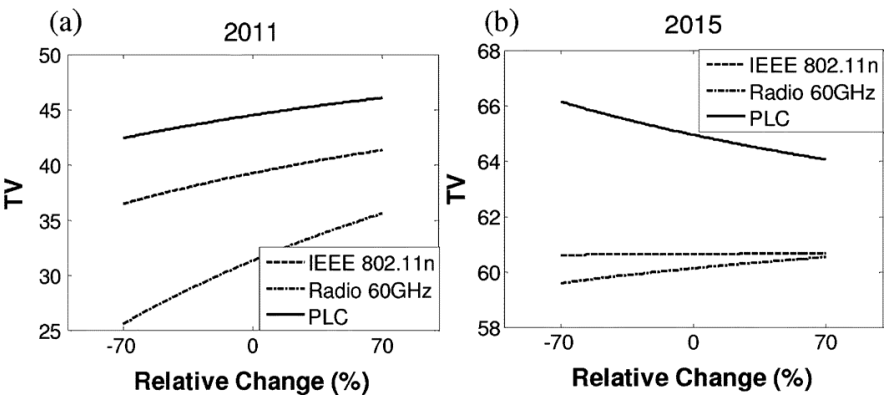

Fig. 8. Sensitivity of alternatives for performance changes from $-70 \%$ to $70 \%$ : (a) 2011 and (b) 2015 .

a hybrid solution incorporating both would present with interesting prospects compared to HNS incorporating only a single technology.

\section{Sensitivity ANALYsis}

The results obtained in the previous section may be undermined by uncertainties involved in the evaluation of priorities or the technological metric forecasts, which according to Fig. 2 are essential elements for evaluating the technology values. In this section we discuss the reliability of the results against uncertainty by carrying out a sensitivity analysis. In Section V-A, we consider the impact of changing primarily the value of a weight of a single criterion or factor while in Section V-B, we use Monte Carlo simulation to estimate the effect of simultaneously introducing random perturbations in these weights. In Section $\mathrm{V}-\mathrm{C}$, we discuss the changes in technology value when a single technological metric is varied, whereas in Section V.D. Monte Carlo simulations are performed to study the effect of changing many of these metrics simultaneously.

\section{A. Changes in Primarily a Single Component}

Fig. 8(a) and (b) illustrate the influence of perturbing the weight of the performance criterion in the technology value of the alternatives in 2011 and 2015 respectively. It should be noted that the weights need to be normalized so that $\Sigma_{k} w_{k}=1$ and consequently changing a single weight will necessarily induce changes in the weights of other criteria as well because of the renormalization. Fig. 8(a) suggests that changing $w_{1}$ affects the TV of all three technologies. In 2011, the TV of $60 \mathrm{GHz}$ systems changes significantly. The changes are less significant in 2015, because as indicated in Fig. 6(a) and (b) the technology value of the performance criterion becomes less important towards the end of the study period. It is also interesting to note that the ranking between the various alternatives is preserved both in 2011 and 2015 even for relative changes as high as $\pm 70 \%$. Similar conclusions are drawn when the sensitivity analysis is carried out for the weight of trustworthiness/confidence, which is the criterion with the highest weight in Table I. Fig. 10 illustrates the effect of changing the weight of the downstream bit rate factor, while Fig. 11 considers the sensitivity analysis for the weight of the health issues factor, (the most important factor of the trustworthiness/confidence criterion). In both cases, the factor weights are renormalized so that $\Sigma_{j} f_{j k}=1$. It is interesting to note that the ranking is again preserved both in 2011 and 2015. 

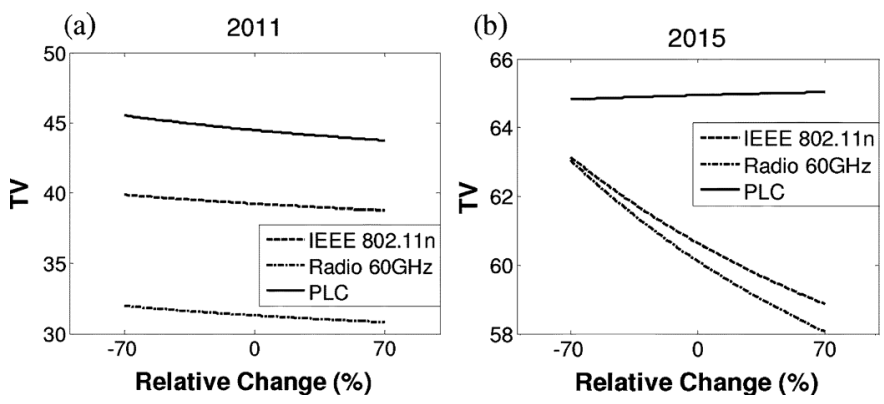

Fig. 9. Sensitivity of alternatives for system trustworthiness/confidence changes from $-70 \%$ to $70 \%$ : (a) 2011 and (b) 2015 .
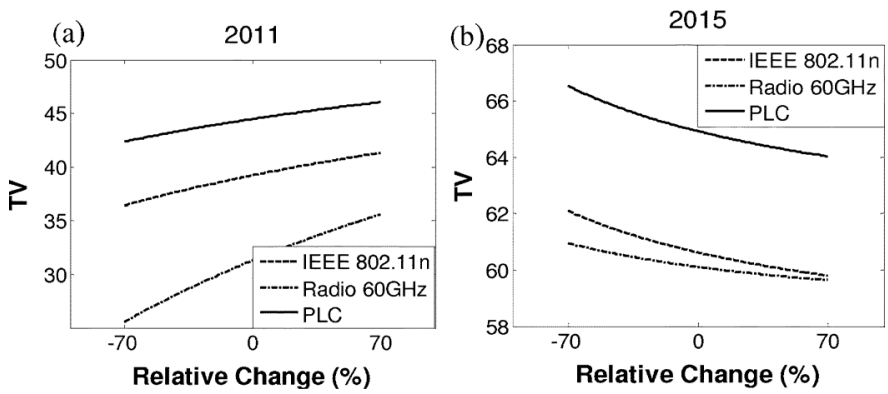

Fig. 10. Sensitivity of alternatives for downstream bit rate changes from $-70 \%$ to $70 \%$ : (a) 2011 and (b) 2015 .
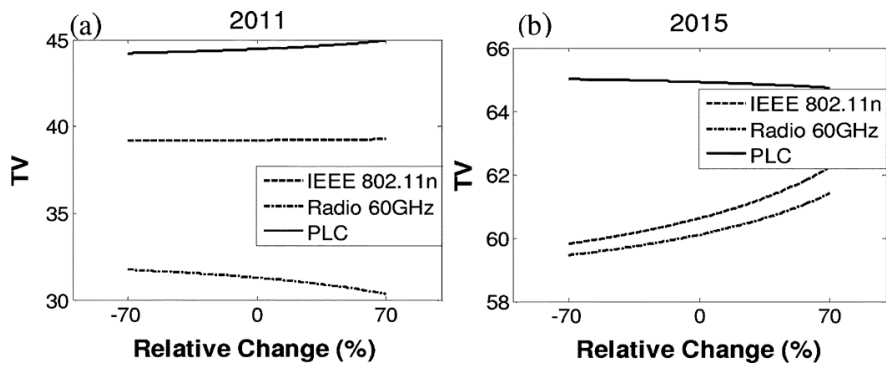

Fig. 11. Sensitivity of alternatives for health issues changes from $-70 \%$ to 70\%: (a) 2011 and (b) 2015.

\section{B. Simultaneous Changes of Criteria/Factors Weights}

In order to evaluate the impact of simultaneously changing more than one weight, one can resort to Monte Carlo simulations. We perturb the weights of all criteria and factors from $w_{k}$ and $f_{j k}$ to $w_{k}\left(1+\Delta W_{k}\right)$ and $f_{j k}\left(1+\Delta F_{j k}\right)$ where the perturbations $\Delta W_{k}$ and $\Delta F_{j k}$ are assumed zero mean, identically distributed independent random variables. These random variations can be due for example to the fact that the experts may perform inconsistent pair wise comparisons [43]. In Fig. 12(a) and (b), we show the histogram of the technology values of $802.11 \mathrm{n}$ and PLC in 2015 respectively, obtained when $\Delta W_{k}$ and $\Delta F_{j k}$ are randomly chosen from a uniform distribution inside $[-s s]$ where $s$ is taken equal to 0.1 (corresponding to a maximum $\pm 10 \%$ variation with respect to its original value). After the weights are randomly chosen they must be renormalized so that $\Sigma_{k} w_{k}=1$ and $\Sigma_{j} f_{j k}=1$. The technology values of $802.11 \mathrm{n}$ and PLC were calculated using $10^{5}$ Monte Carlo iterations. Interestingly enough, it seems that technology exhibit a similar sensitivity for both technologies and that the TVs in
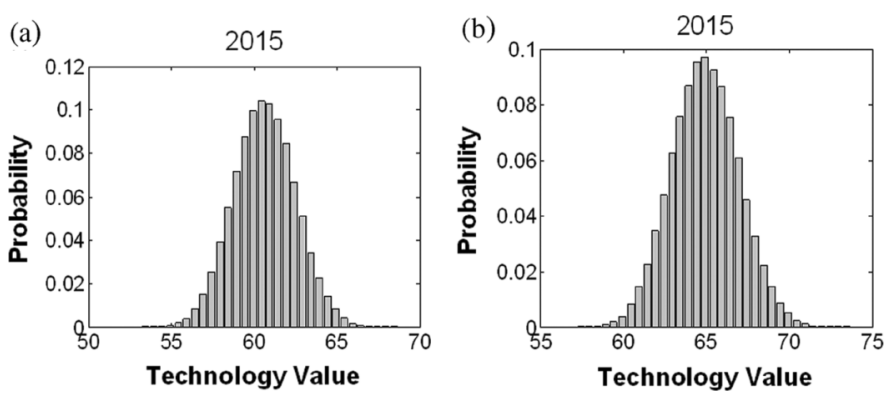

Fig. 12. Sensitivity of TV histogram in 2015 for (a) IEEE 802.11n and (b) PLC.

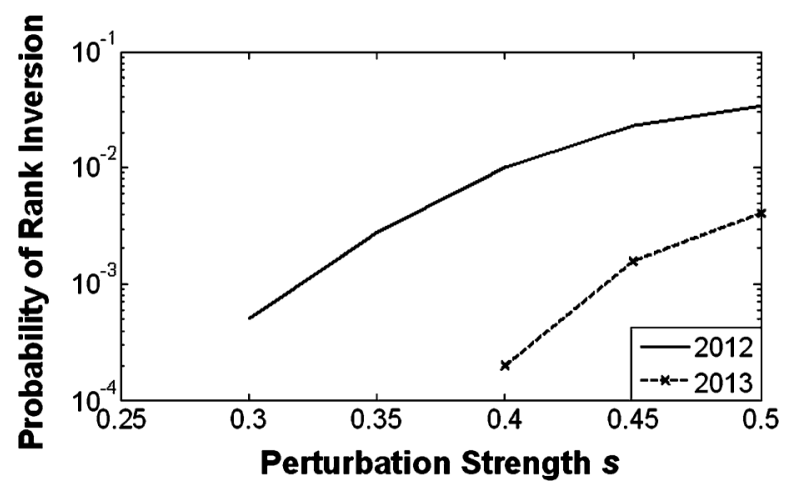

Fig. 13. Rank Inversion Probability as a function of the perturbation strength

2015 are somewhat more prone to uncertainty-induced perturbations.

Monte Carlo simulation can be used to evaluate the probability of rank inversion [43] as well. In our case, we can estimate the probability of rank inversion by measuring the number of iterations in which the technology ranking turns out to be different than that illustrated in Section IV. Fig. 13 shows the probability of rank inversion between the two most prominent technologies (PLC and IEEE 802.11n) for 2012 and 2013. The perturbations strength now ranges from 0.1 to 0.5 . It is interesting to note that the probability of rank inversion is zero for small perturbations. Interestingly enough, the ranking order is always preserved in 2011, 2014, 2015, where according to Fig. 5 the unperturbed TV of PLC and IEEE802.11n differ significantly. In 2012 and 2013, the probability of rank inversion is rather high only for strong perturbations $(s>0.3)$.

\section{Changes in Primarily a Single Technological Metric}

Given that the future values $t_{n j k}$ of factors are based on experts forecasting ability according to their experience, a sensitivity analysis is also for $t_{n j k}$. Fig. 14(a) and (b) depict the change in TV brought by varying the technological metrics of downstream bit rate and range factors from their values $t_{n 31}, t_{n 11}$, respectively, in 2015. As shown in Fig. 14, the variations induce changes in the TV of all three technologies compared to its base value (shown in dash lines). Interestingly enough, Fig. 14(a) illustrates that PLC remains the most highly ranked solution unless $t_{n 31}$ becomes $\cong 50 \%$ smaller for PLC and $\cong 50 \%$ larger for 802.11 n. Fig. 14(b) illustrates that for 
(a)
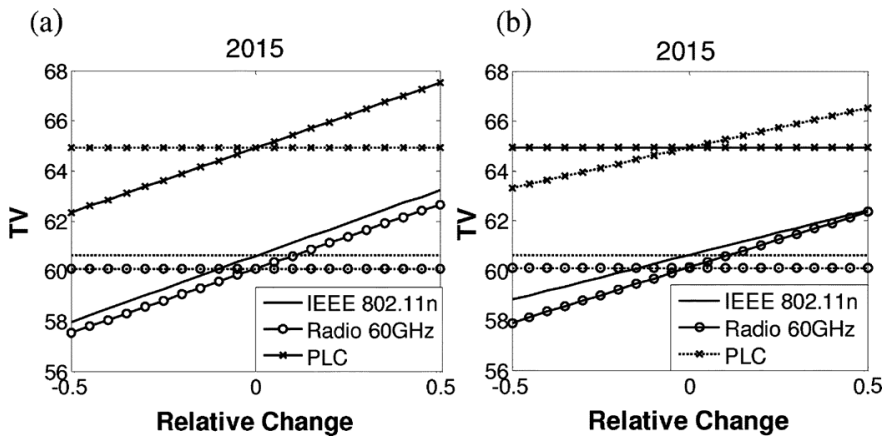

Fig. 14. Sensitivity of alternatives for a single technological metric changes from $-50 \%$ to $50 \%$ : (a) downstream bit rate (b) range. Dash lines correspond to base values.
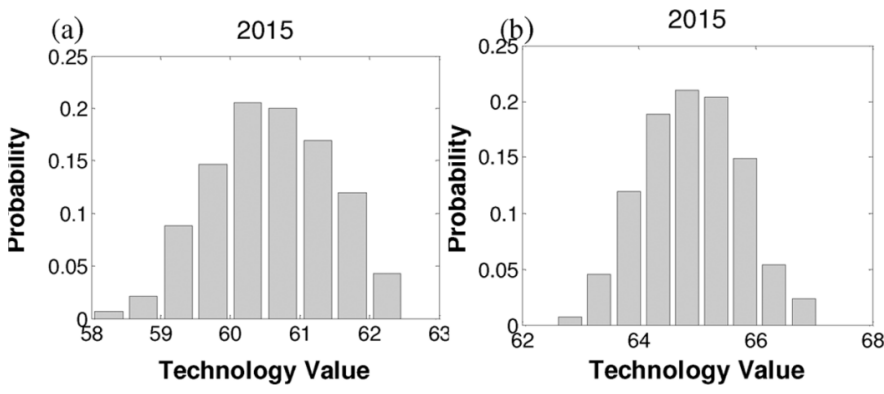

Fig. 15. Sensitivity of TV histogram: (a) IEEE $802.11 \mathrm{n}$ and (b) PLC.

PLC is always the highly ranked solution even if the range forecasts change dramatically.

\section{Simultaneous Changes of Performance Factors Technological Metrics}

In this section, a sensitivity analysis using Monte Carlo simulation is performed in order to further examine how the forecasting uncertainty influences the TV of the alternatives. The technological metrics of all performance factors are simultaneously perturbed in a fashion similar to II.B. Fig. 15(a), (b) depict the sensitivity of TV histogram the most prominent technology alternatives (IEEE802.11n and PLC respectively) in 2015. The perturbation strength is $s=0.5$ corresponding to a maximum deviation of $25 \%$ from the original values. The figure illustrates that forecasting uncertainties do influence the value of $\mathrm{TV}$, but not dramatically. The results of the present section provide an indication of the reliability of the AHP results against uncertainties in the pairwise comparisons and the forecasts carried out by the experts.

\section{CONCLUSION}

In this paper, the home networking system related roadmapping activities carried out within the ICT-OMEGA project have been presented and discussed. Using the AHP the ranking of the various technological alternatives comprising of IEEE802.11, $60 \mathrm{GHz}$ systems and PLC has been accomplished. The results focus on network extension but are also indicative for the rest of the home network components as well. AHP indicates that PLC takes some precedence over the wireless alternatives. IEEE802.11 is ranked second best while $60 \mathrm{GHz}$ system are regarded as a longer term alternative, which could provide gigabit per second connectivity. The paper also discussed the merits of hybrid integration of these technologies, either in the PHY or a higher network layer. Indeed, PLC would be the most ubiquitous connection in the home, while all the devices would include additional interface to support the benefits of intelligent switching to include a wireless extension. A sensitivity analysis was also performed in order to estimate the uncertainties involved and it was deduced that they do not in general undermine the results of the ranking.

\section{ACKNOWLEDGMENT}

The authors would like to thank the experts participated in the aforementioned surveys as well as the people working on the Workpackage 1 of ICT-OMEGA. They would like also to appreciate the valuable contribution of K. Papadogeorgaki and G. Kakaletris, both from the University of Athens, Greece, to the design, development and maintenance of the survey/roadmapping platform.

\section{REFERENCES}

[1] P. W. Shumate, "Fiber-to-the-Home: 1977-2007," IEEE J. Lightwave Technol., vol. 26, pp. 1093-1103, 2008.

[2] J. P. Javaudin, M. Bellec, P. Jaffré, A. Foglar, O. Hoffmann, and O. Isson, "Inter-MAC concept for gigabit home networks," presented at the 2009 PIMRC, Tokyo, Japan.

[3] D. C. O'Brien, "Cooperation in optical wireless communications," Springer Cooperation in Optical Wireless Communications 2007.

[4] L. Ophir, Y. Bitran, and I. Sherman, "Wi-Fi (IEEE 802.11) and Bluetooth coexistence: Issues and solutions," in 2004 Personal, Indoor and Mobile Radio Communications, 15th IEEE International Symposium, vol. 2, pp. 847-852.

[5] Technical Characteristics of Multiple Gigabit Wireless Systems in the $60 \mathrm{GHz}$ Range ETSI TR 102 555, System Reference Document.

[6] R. Kraemer and M. Katz, Short-Range Wireless Communications: Emerging Technologies and Applications. Hoboken, NJ: Wiley, 2009.

[7] K. H. Afkhamie, S. Katar, L. Yonge, and R. Newman, "An overview of the upcoming HomePlug AV standard," presented at the 2005 International Symposium on Power Line Communications and Its Applications,

[8] OMEGA Architecture Model Dec. 2008 [Online]. Available: http:// www.ict-omega.eu

[9] T. L. Saaty, "Decision making with the analytic hierarchy process," Int. J. Services Sci., vol. 1, no. 1, 2008.

[10] N. Gerdsri and D. F. Kocaoglu, "Applying the analytic hierarchy process (AHP) to build a strategic framework for technology roadmapping," Math. Comput. Model., vol. 46, pp. 1071-1080, 2007.

[11] C. W. Chang, C. R. Wu, C. T. Lin, and H. C. Chen, "An application of AHP and sensitivity analysis for selecting the best slicing machine," Comput. Ind. Eng., vol. 52, no. 2, pp. 296-307, Mar. 2007.

[12] G. Dede, D. Varoutas, T. Kamalakis, R. G. Fuentetaja, and J. P. Javaudin, "Netnomics: Economic Research and Electronic Networking," in Evaluation of Technological and Socio-Economic Issues Affecting the Deployment of Home Networks: Evidence From the ICT-OMEGA Project. Berlin, Germany: Springer, 2010, vol. 11, pp. 281-200.

[13] Ch.-Ch. Huanga, P.-Y. Chub, and Y.-H. Chiangb, "A fuzzy AHP application in government-sponsored R\&D project selection," Omega, vol. 36, pp. 1038-1052, 2008.

[14] Y. Lee and K. A. Kozar, "Investigating the effect of website quality on e-business success: An analytic hierarchy process (AHP) approach," Dec. Support Syst., vol. 42, pp. 1383-1401, 2006.

[15] F. T. S. Chan, H. K. Chan, H. C. W. Lau, and R. W. L. Ip, "An AHP approach in benchmarking logistics performance of the postal industry," Int. J. Benchmarking, vol. 13, pp. 636-666, 2006.

[16] M. J. Liberatore and R. L. Nydick, "The analytic hierarchy process in medical and health care decision making: A literature review," Eur. J. Oper. Res., vol. 189, pp. 194-207, 2008.

[17] P. R. Drake, "Using the analytic hierarchy process in engineering education," Int. J. Eng. Educ., vol. 14, pp. 191-196, 1998. 
[18] C. Y. T. Maggie and V. M. R. Tummala, "An application of the AHP in vendor selection of a telecommunications system," Int. J. Manag. Sci., vol. 29, pp. 171-182, 2001.

[19] M. J. DiMario, J. T. Boardman, and B. J. Sauser, "System of systems collaborative formation," IEEE Syst. J., vol. 3, no. 3, pp. 360-368, Sep. 2009.

[20] O. Bouchet, P. Porcon, P. J. W. Walewski, S. Nerreter, K.-D. Langer, L. Fernández, J. Vučić, T. Kamalakis, G. Ntogari, I. Neoskosmidis, and E. Gueutier, "Wireless optical network for a home network," in Proc. SPIE, 2010, 7814, art. no. 781406.

[21] R. Saeed, S. Khatun, B. M. Ali, and M. K. Abduallah, "Ultra wide band (UWB) ad-hoc networks: Review and trends," J. Comput. Sci., vol. 1, pp. 35-39, 2005.

[22] M. Kwiesielewicz and M. Van Uden, "Inconsistent and contradictory judgments in pairwise comparison method in the AHP," Comput. Oper. Res., vol. 31, pp. 713-719, 2004.

[23] T. L. Saaty, "How to make a decision: The analytic hierarchy process," Eur. J. Oper. Res., vol. 48, pp. 9-26, 1990.

[24] N. Kuster and F. Schönborn, "Recommended minimal requirements and development guidelines for exposure setups of bio-experiments addressing the health risk concern of wireless communications," Bioelectromagnetics, vol. 21, pp. 508-514, 2000.

[25] IEEE Standard for Safety Levels With Respect to Human Exposure to Radio Frequency Electromagnetic Fields, $3 \mathrm{kHz}$ to $300 \mathrm{GHz}$, Std. C95.1-2005, 2005.

[26] F. R. Kenneth, "Radiofrequency exposure from wireless lans utilizing Wi-Fi technology," Health Phys., vol. 92, pp. 280-289, 2007.

[27] Board Wireless Lan Medium Access Control (MAC) and Physical Layer (PHY) Specifications 2007, IEEE-SA Standards IEEE.

[28] A. Majumder and J. Caffery, Jr., "Power line communications," IEEE Potentials, vol. 24, pp. 4-8, 2004.

[29] A. Oram, Peer-to-Peer: Harnessing the Power of Disruptive Technologies. Sebastopol, CA: O'Reilly \& Associates, Inc., 2001.

[30] ICT-OMEGA, Focus Group Sessions Report Apr. 2009 [Online]. Available: https://www.ict-omega.eu, Deliverable 1.4, ril)

[31] C. M. Ta, B. Wicks, F. Zhang, B. Yang, Y. Mo, K. Wang, Z. Liu, G. Felic, P. Nadagouda, T. Walsh, R. J. Evans, I. Mareels, and E. Skafidas, "Issues in the implementation of a $60 \mathrm{GHz}$ transceiver on CMOS," presented at the The 2007 2nd IEEE International Workshop on RadioFrequency Integration Technology, Singapore.

[32] TG3cwebpage [Online]. Available: [Online]. Available: http://www. ieee802.org/15/pub/TG3c.html

[33] Y. H. Ma, P. L. So, and E. Gunawan, "Performance analysis of OFDM systems for broadband power line communications under impulsive noise and multipath," IEEE Trans. Power Del., vol. 20, pp. 674-681, Apr. 2005.

[34] K. S. Al-Mawali, F. S. Al-Qahtani, and Z. M. Hussain, "Adaptive power loading for OFDM-based power line communications impaired by impulsive noise," presented at the 2010 IEEE ISPLC - International Symposium on Power Line Communications and Its Applications,

[35] M. Huchard, M. Weiss, A. Pizzinat, S. Meyer, P. Guignard, and B. Charbonnier, "Ultra-broadband wireless home network based on 60-GHz WPAN cells interconnected via RoF," J. Lightwave Technol., vol. 26, pp. 2364-2372, 2008.

[36] M. S. Gast, 802.11 Wireless Networks: The Definitive Guide, 2nd ed. Sebastopol, CA: O'Reilly Media, 2005.

[37] N. Guo, R. C. Qiu, S. S. Mo, and K. Takahashi, "EURASIP Journal on Wireless Communications and Networking," in 60-GHzMillimeter-Wave Radio: Principle, Technology, and New Results. Mumbai, India: Hindawi, 2007, Article ID 68253, 8 pages.

[38] Z. Genc, B. L. Dang, J. Wang, and I. Niemegeers, "Home networking at $60 \mathrm{GHz}$ : Challenges and research issues," Ann. Telecommun., vol. 63, pp. 501-509, 2008.
[39] J. M. Wilson, "The next generation of wireless LAN emerges with 802. 11n," Technology Intel Magazine 2004.

[40] L. L. Yang, "60 GHz: Opportunity for gigabit WPAN and WLAN convergence," ACM SIGCOMM Comput. Commun. Rev., vol. 39.

[41] B. Olsen and K. Stordahl, "Models for forecasting cost evolution of components and technologies," Telektronikk, vol. 100, pp. 138-148, 2004.

[42] T. Komine and M. Nakagawa, "Integrated system of white LED visible-light communication and power-line communication," IEEE Trans. Consumer Electron., vol. 49, pp. 71-79, Feb. 2003.

[43] T. L. Saaty and L. G. Vargas, "Inconsistency and rank preservation," J. Math. Psychol., vol. 28, pp. 205-214, 1984.

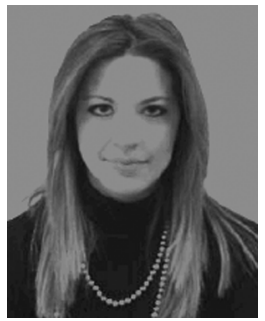

Georgia Dede received the degree in informatics and telecommunications in 2005 and the M.Sc. degree in administration and economics of telecommunication networks in 2007 from the University of Athens, Greece, where he is currently pursuing the Ph.D. degree.

Since 2007, she is an Adjunct Lecturer and Research Associate in the Department of Informatics and Telematics, Harokopio University of Athens.

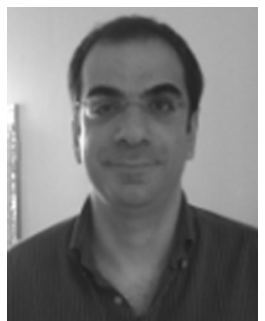

Thomas Kamalakis (M'09) received the B.Sc. degree in informatics, the M.Sc. degree in telecommunications (with distinction) and the Ph.D. degree in integrated optics, all from the University of Athens, Greece, in 1997, 1999 and 2004, respectively.

Since 2005, he is a Research Associate of the Optical Communications Laboratory, University of Athens. In 2008, he was appointed Lecture in the Department of Informatics and Telematics, Harokopio University of Athens. He is the author and co-author of more than 50 publications in scientific journals and conferences in the fields of optical communications and techno-economics.

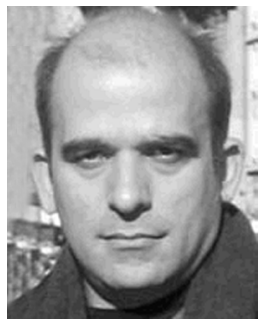

Dimitris Varoutas (M'03) received the physics degree and the M.Sc. and Ph.D. degrees in communications and technoeconomics from the University of Athens, Greece.

$\mathrm{He}$ is an Assistant Professor of telecommunications technoeconomics in the Department of Informatics and Telecommunications, University of Athens. His researcher interests include technoeconomic evaluation of broadband strategies, telecommunications demand forecasting, systems assessment, etc. He has published more than 70 publications in journals and conferences. Dr. Varoutas serves as reviewer of several journals and conferences. He actively participates in several technoeconomic activities for telecommunications projects, as well as the Conferences on Telecommunications TechnoEconomics. 